Intropica 14(1): 51 - 59

\title{
Respuestas del maíz que indican que el paclobutrazol induce mayor actividad genética
}

\section{Maize responses that indicate that the Paclobutrazol induces higher genetic activity}

\author{
Teresa Velázquez-Alcaraz@, Tomás Diaz-Valdés@, Felipe Ayala-Tafoya®, Moisés G. Yáñez-Juárez@,

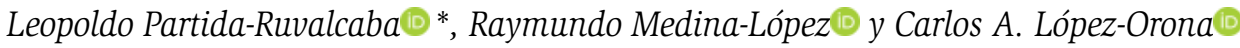

*Autor de correspondencia: parpolo@yahoo.com.mx

Recibido: 11 septiembre de 2018

Aceptado: 13 febrero de 2019

Universidad Autónoma de Sinaloa, Sinaloa, México

\begin{abstract}
Resumen
Palabras clave:

ácidos nucleicos; síntesis de proteínas; rendimiento del grano

de maíz

El objetivo de esta investigación fue determinar el efecto que produce el paclobutrazol (PBZ) en la actividad genética de los cultivares de maíz Puma 1076, 30P49 y DK2020 a través de la evaluación de las variables de respuesta verdor, altura de planta, diámetro del tallo, longitud y ancho de hoja, peso y volumen de 1000, contenido de proteína y rendimiento de grano por hectárea. El diseño experimental fue de bloques completos al azar, con cinco repeticiones en dos experimentos realizados durante los ciclos agrícolas 2008-2009 y 2009-2010. En el primer ciclo se utilizaron parcelas de cuatro surcos de $40 \mathrm{~m}$ de largo, donde se aplicó $200 \mathrm{~kg}$ de $\mathrm{N} \mathrm{ha}^{-1}$, mientras que en el segundo experimento la longitud de las parcelas fue de 5,0 m y se fertilizó con $250 \mathrm{~kg}$ de $\mathrm{N} \mathrm{ha}^{-1}$. Las dosis de PBZ fueron 150, 300 y 450 $\mathrm{mg} \mathrm{L}^{-1}$ de agua al exponerse la cuarta, sexta y octava hoja verdadera, respectivamente. Los resultados indicaron que el PBZ indujo mayor actividad genética, ya que la síntesis de proteínas y de otros componentes de células, tejidos y órganos es un proceso que depende de la transcripción de mensajes del ADN en el ARNm, de la síntesis de aminoácidos, del transporte de aminoácidos por el ARNt y de la unión de aminoácidos por la enzima peptidil transferasa, lo que conlleva a la traducción de mensajes en proteínas estructurales y activas (enzimas), para formar más células y sustancias que constituyen a estas y, en consecuencia, ocasionar más rendimiento de grano por hectárea.
\end{abstract}

Key words:

nucleic acids; protein synthesis; corn grain yield

\section{Abstract}

The aim of the research was to determine the effect of Paclobutrazol (PBZ) in the genetic activity of the maize cultivars Puma, 30P49 and DK2020, through the evaluation of response variables greenness, height of plant, stem diameter, leaf length and width, weight and volume of 1000 grains, protein content and grain yield per hectare. The experimental used was randomized complete blocks design with five replicates in two experiments performed during the 2008-2009 and 2009-2010 agricultural cycles; in the first cycle plots of four row of $40 \mathrm{~m}$ of long were used, where $200 \mathrm{~kg}$ of $\mathrm{N} \mathrm{ha}{ }^{-1}$ were applied; while in the second the length of plots was $5.0 \mathrm{~m}$ and fertilized with $250 \mathrm{~kg}$ of $\mathrm{N} \mathrm{ha}^{-1}$. The doses were 150,300 and $450 \mathrm{mg}_{\text {of PBZ L}}{ }^{-1}$ of water until exposure of the fourth, sixth and eighth true leaf, respectively. The results indicated that PBZ induced greater genetic activity, since the synthesis of proteins and other components of cells, tissues and organs is a process that depends on the transcription of DNA messages in mRNA, amino acid synthesis, the transport of amino acids by tRNA and the binding of amino acids by the enzyme Peptidyl Transferase, which leads to the translation of messages into structural and active proteins (enzymes), to form more cells and substances that constitute them and consequently, cause more grain yield per hectare. 
El paclobutrazol (PBZ) es un regulador del crecimiento del grupo de los triazoles que ha sido registrado como inhibidor de la biosíntesis del ácido giberélico que incrementa el contenido de citocininas y ácido abscísico. Además, aumenta considerablemente el total de fenoles en la especie Ocimum sanctum (Gopi et al., 2009). En la palma de aceite (Elaeis quineensis Jacq.), el PBZ incrementa la superficie epicuticular de las raíces, el color verde de las hojas y el contenido total de clorofila a 3,54 $\mathrm{mg} \mathrm{g}^{-1}$ de peso fresco (Nizam y Te-chato, 2009). Goulston y Shearing (1985) registraron que, en plantas de Nochebuena, aplicaciones de paclobutrazol dirigidas al suelo y follaje redujeron la altura de estas y produjeron especímenes más compactos, con un follaje verde oscuro.

Partida et al. (2007) observaron que el PBZ incrementó la biomasa de raíz y de la parte aérea en pimiento morrón y berenjena, con relación al testigo. En pimiento morrón, $150 \mathrm{mg} \mathrm{L}^{-1}$ fue la dosis más adecuada al aumentar 1,1 veces la longitud de raíz, 3,7 veces la materia fresca y 13 veces la materia seca, y al incrementar en 1,5 y 6,7 veces la materia fresca y la seca de la parte aérea, respectivamente. En raíces de berenjena, el incremento fue de 1,3 veces la materia fresca y de $71 \%$ la materia seca de raíz, y de $81 \%$ la materia fresca y 89 \% la materia seca de la parte aérea.

El PBZ es un retardante usado con frecuencia en plantas ornamentales para controlar su crecimiento y compactarlas, de tal manera que en plántulas de la especie Nerium oleander reduce significativamente todos los parámetros de crecimiento, lo que da lugar a plantas más compactas y de buen valor comercial cuando se aplica al suelo. Sin embargo, con este procedimiento suele ser persistente en el suelo (Ochoa et al., 2009).

Mediante dosis de 12 y $24 \mathrm{~mL} \mathrm{~L}^{-1}$ de PBZ, combinado con 75 y $150 \mathrm{~kg}$ de $\mathrm{N} \mathrm{ha}^{-1}$, respectivamente, esta sustancia disminuye la altura y madurez de las plantas de maíz, pero también incrementa el grosor del tallo y el rendimiento de materia seca. Así mismo ocurre con el contenido de la clorofila a y b con relación a las plantas testigo (Iremiren et al., 2002).

En Ficus benjamina, la producción y el tamaño de la hoja fueron caracteres reducidos cuando el medio fue humedecido con PBZ (LeCain et al., 1986). También en árboles de pecana (Carya illinoensis (Wangenh) C. Koch) se disminuyó el crecimiento de raíces y el área foliar durante cuatro años después que las plantas fueron tratadas (Wood, 1988).

El PBZ es un activo inhibidor de la biosíntesis del ácido 52 giberélico (Tadao et al., 2000) que ha sido usado para retardar la elongación del tallo, y en ocasiones para promover la floración en plantas ornamentales leñosas (Wilkinson y Richards, 1988). En hojas de maíz (Zea mays), de los cultivares 3902 de Pioneer y Orgullo 5, el PBZ ocasionó que los cloroplastos fueran más grandes y, asimismo, que se incrementara el número de lamelas del estroma y de pilas de grana (Sopher et al., 1999).

En diversos tipos de vegetales se pueden encontrar cloroplastos de diferente tamaño y formas (Possingham, 1980), los cuales cuando son jóvenes se dividen de forma activa, especialmente si el órgano que los contiene se expone a la luz. Por lo tanto, a menudo cada célula de una hoja madura posee cientos de cloroplastos que contienen estroma con enzimas que convierten el $\mathrm{CO}_{2}$ en carbohidratos, sobre todo en almidón, tilacoides (lamelas) y grana (pilas de tilacoides), constituidos por dos membranas, en donde se almacena la clorofila (Salisbury y Ross, 2000).

Los mensajes contenidos en el ADN se transcriben en las moléculas de ARNm para traducirse en los ribosomas con actividad de los ARNt, los ARNr y enzimas como la endonucleasa, la peptidil transferasa, la aminoacil sintetasa, entre otras. De esta manera sintetizan las proteínas estructurales o activas (enzimas), que a su vez son transportadas a las partes celulares demandantes para formar parte de los orgánulos o estructuras celulares (Strickberger, 1978). De acuerdo con Freifelder (1988) y con Lea y Leegood (1993), el almidón, los aminoácidos y las proteínas forman parte de las células vegetales, las cuales para su síntesis necesitan de mensajes contenidos en el código genético que conforman los codones del ADN.

De acuerdo con Strickberger (1978), Conn y Stumpf (1980) y Ferreira et al. (2005), para metabolizar el nitrógeno y el magnesio en las moléculas de clorofila, se requirieron todas aquellas enzimas que sólo pudieron sintetizarse por la transcripción de mensajes del ADN en el ARNm y la traducción de éstos en los ribosomas, donde necesariamente también participó mayor cantidad de enzimas en la unión de aminoácidos, como la aminoacilARNt Sintetasa y la peptidil Transferasa, mismas que se constituyeron por la previa síntesis de los aminoácidos necesarios en su composición. El objetivo de esta investigación fue determinar si el Paclobutrazol promueve mayor actividad genética en el maíz.

La investigación se realizó en el campo experimental de la facultad de Agronomía de la Universidad Autónoma de Sinaloa, ubicada en el kilómetro 17,5 de la carretera Culiacán-Eldorado, con coordenadas $24^{\circ} 37^{\prime} 29^{\prime \prime} \mathrm{N}$ y $107^{\circ}$ 26' 36" O. En el primer experimento, conducido en el ciclo 
agrícola 2008-2009, solo se utilizó el cultivar Puma, y en el ciclo 2009-2010 se evaluaron, además, 30P49 y DK2020. Durante el ciclo 2008-2009, la siembra se llevó a cabo el 19 de diciembre de 2008, en tanto que en el ciclo 20092010 se hizo el 8 de diciembre de 2009. En los dos casos se formaron hileras sencillas y bajo condiciones de campo abierto, en un diseño experimental de bloques completos al azar con cinco repeticiones.

Para la variedad Puma en el ciclo 2008-2009, las parcelas experimentales constaron de cuatro surcos de $40 \mathrm{~m}$ de largo, y las parcelas útiles fueron los dos surcos centrales, con separación de 0,80 m entre sí. Sobre ellos se hizo la siembra a tierra venida, ya que el suelo es de textura arcillosa y se dió un riego por gravedad antes de la siembra, así como los riegos de auxilio por gravedad (tres) necesarios para inducir el crecimiento y desarrollo de las plantas. Todas las parcelas experimentales del primer ciclo se manejaron con $200 \mathrm{~kg}$ de $\mathrm{N} \mathrm{ha}^{-1}$ a partir de urea, aplicando el $100 \%$ en el momento de la escarda, antes del primer riego de auxilio; además, las plantas se protegieron con el insecticida Paratión Metílico 720 para combatir el gusano cogollero. Previo a la siembra se hizo análisis del suelo para conocer algunas de sus propiedades físicas y químicas, tales como $\mathrm{pH}=7,6$, conductividad eléctrica $(\mathrm{CE})=0,92 \mathrm{dS} \mathrm{m}^{-1}$, materia orgánica $(\mathrm{MO})=0,86$, relación de adsorción del sodio $(\mathrm{RAS})=1,1$, nitrógeno total $(\mathrm{N})=$ $147 \mathrm{~kg} \mathrm{ha}^{-1}$ y fósforo total $(\mathrm{P})=28,7 \mathrm{~kg} \mathrm{ha}^{-1}$.

Por otra parte, en el ciclo 2009-2010 la siembra también se hizo en surcos separados a $0,80 \mathrm{~m}$, pero en parcelas experimentales de 5,0 $\mathrm{m}$ de largo. El manejo en este caso incluyó la fertilización con $250 \mathrm{~kg}$ de $\mathrm{N} \mathrm{ha}^{-1}$ a partir de urea y la aplicación de cuatro riegos de auxilio por gravedad y de Paratión Metílico 720 para controlar el gusano cogollero.

En los dos ciclos, la densidad de población fue de 11 plantas por metro lineal, lo que ocasionó una población de 137.500 plantas por hectárea, lo cual resulta de multiplicar 11 plantas X 100 m de largo de los surcos X 125 surcos que se pueden construir en $100 \mathrm{~m}$ de ancho de la parcela.

Las variables de estudio fueron: contenido de clorofila, altura de planta, diámetro del tallo, longitud y anchura de hojas, peso y volumen de 1000 granos, contenido de proteína y rendimiento de grano por hectárea. En cuanto a los tratamientos aplicados, estas fueron las dosis de 0 (testigo), 150, 300 y $450 \mathrm{mg}^{\mathrm{de}} \mathrm{PBZ} \mathrm{L}^{-1}$ de agua. La dosis de $150 \mathrm{mg}$ de $\mathrm{PBZ} \mathrm{L}^{-1}$ de agua se aplicó en una sola ocasión, mientras que las de 300 y 450 se completaron a través de dos y tres aplicaciones con $150 \mathrm{mg}$ de $\mathrm{PBZ} \mathrm{L}^{-1}$ de agua, respectivamente, con una bomba manual. La primera aplicación del PBZ se hizo cuando las plantas tuvieron cuatro hojas verdaderas, mientras que la segunda y la tercera se hicieron ocho días después de la que las precedió, de tal manera que las plantas tuvieron las respectivas seis y ocho hojas verdaderas.

Todas las variables, excepto el contenido de proteína, se evaluaron en una muestra de 20 plantas seleccionadas al azar. El contenido de clorofila se midió en unidades SPAD502, en la parte media de la lámina foliar (específicamente, a un lado de la nervadura central), y los datos se recabaron ocho días después de cada aplicación (en aquellos casos donde se realizaron hasta tres aplicaciones, la medición se llevó a cabo antes de la siguiente aplicación). La altura se estableció a partir de la superficie del suelo hasta la base de la inflorescencia masculina. El diámetro del tallo se midió utilizando vernier en el entrenudo localizado entre la segunda y la tercera hoja verdadera, considerando la parte más ensanchada de este. La longitud y la anchura de las hojas se determinaron con cinta métrica en la octava hoja de abajo hacia arriba: la primera desde la vaina hasta el ápice de las hojas, y la segunda en la parte central de la lámina foliar.

El peso de 1000 granos se obtuvo con una báscula de precisión marca Ohaus con capacidad de 2610 g. El volumen se constató con una probeta de $500 \mathrm{~mL}$, a través de la diferencia del total de mililitros de agua base y el valor observado después de depositar los 1000 granos. Para el contenido de proteína se utilizó el método Kjeldahl, y solo se hizo en el grano de la variedad Puma que se sembró en el ciclo agrícola 2009-2010, en tanto que el rendimiento se determinó con base en la producción obtenida en la cantidad de metros cuadrados de las parcelas útiles. Los datos se analizaron estadísticamente con el procedimiento PROC GLM del SAS Institute (1996), versión 6.12, utilizando la prueba de comparación múltiple de promedios Tukey, con $\alpha \leq 0,05$.

Las dosis de 150, 300 y $450 \mathrm{mg} \mathrm{PBZ} \mathrm{L}^{-1}$ de agua indujeron promedios de verdor (contenido de clorofila) que superaron respectivamente en 3,9, 4,8 y 5,9 \% el promedio observado en el testigo (tabla 1). De tal manera que estos resultados coinciden con los de Iremiren et al. (2002), toda vez que estos autores observaron que las plantas de maíz tratadas con PBZ también fueron más verdes que las plantas testigo.

De manera general, la altura de las plantas fue de 2,26 $\mathrm{m}$, con desviación estándar de $0,15 \mathrm{~m}$ y coeficiente de variación de 6,6\%. Los promedios de altura que se obtuvieron de las plantas tratadas con 150, 300 y 450 mg de PBZ L-1 de agua fueron estadísticamente iguales y 
fueron de 0,9 a $2 \%$ superiores a las de las plantas testigo (tabla 1). De esto se deduce que las plantas con PBZ fueron más eficientes para formar materia seca, así como en el gasto de energía y la fijación de $\mathrm{CO}_{2}$, y contribuyeron más en la conservación del medio ambiente y, en esa medida, en la disminución del calentamiento global. Además, la respuesta en la altura indica que el PBZ en las tres dosis que se utilizaron no disminuyó este carácter, lo que coincide con los resultados de Partida et al. (2007) y Velázquez et al. (2008), quienes observaron incrementos en la altura de plantas de tomate y chiles, respectivamente cuando aplicaron dosis de 250, 300 y $350 \mathrm{mg}^{\text {de }} \mathrm{PBZ} \mathrm{L}^{-1}$ de agua. El diámetro del tallo se expresó con un promedio general de 2,6 cm, con desviación estándar de $0,4 \mathrm{~cm}$ y coeficiente de variación de 15,4\%. Con los promedios obtenidos con cada tratamiento, presentados en la tabla 1 , se estimaron incrementos de 5,5, 0,8 y 4,3 \% en las plantas tratadas con 150, 300 y $450 \mathrm{mg}$ de $\mathrm{PBZ} \mathrm{L}^{-1}$ de agua con respecto al diámetro de tallos de las plantas testigo.

La longitud de hojas presentó un promedio general de $97,8 \mathrm{~cm}$, con una desviación estándar de $4,0 \mathrm{~cm}$ y un coeficiente de variación igual a 4,1\%. No obstante que en esta característica no se observaron diferencias estadísticas significativas (tabla 1), en las plantas tratadas con PBZ hubo incrementos que oscilaron de 0,5 a $1,5 \mathrm{~cm}$ en relación con la longitud de hojas en las plantas testigo. Los datos referidos indican mayor producción de materia seca y área foliar y, en consecuencia, mayor eficiencia en la fijación de $\mathrm{CO}_{2}$, mejoramiento del proceso fotosintético y mayor influencia de las plantas en la disminución del calentamiento global.

Tabla 1. Verdor (V), altura (H), diámetro de tallo (DDT), longitud de hoja (L) y ancho de hoja (A) del cultivar Puma de maíz tratado con PBZ (ciclo agrícola 2008-2009), Diferencia Mínima Significativa (DMSH). Promedios con letras iguales en la misma columna son iguales.

\begin{tabular}{rrrcrr}
\hline $\begin{array}{r}\text { Dosis de PBZ } \\
\left(\mathbf{m g ~ L}^{-1}\right)\end{array}$ & $\begin{array}{r}\mathbf{V} \\
(\mathbf{u} . \text { SPAD) }\end{array}$ & $\begin{array}{r}\mathbf{H} \\
(\mathbf{m})\end{array}$ & $\begin{array}{r}\text { DDT } \\
(\mathbf{c m})\end{array}$ & $\begin{array}{r}\mathbf{L} \\
(\mathbf{c m})\end{array}$ & $\begin{array}{r}\mathbf{A} \\
(\mathbf{c m})\end{array}$ \\
\hline 0 (testigo) & $35,4 \mathrm{a}$ & $2,2 \mathrm{a}$ & $2,5 \mathrm{a}$ & $96,9 \mathrm{a}$ & $8,7 \mathrm{a}$ \\
150 & $36,8 \mathrm{a}$ & $2,2 \mathrm{a}$ & $2,7 \mathrm{a}$ & $97,4 \mathrm{a}$ & $8,3 \mathrm{a}$ \\
300 & $37,1 \mathrm{a}$ & $2,2 \mathrm{a}$ & $2,5 \mathrm{a}$ & $98,3 \mathrm{a}$ & $8,5 \mathrm{a}$ \\
450 & $37,5 \mathrm{a}$ & $2,2 \mathrm{a}$ & $2,6 \mathrm{a}$ & $98,3 \mathrm{a}$ & $8,4 \mathrm{a}$ \\
$\mathrm{DMSH}$ & 2,2 & 0,07 & 0,1 & 2,07 & 0,39 \\
\hline
\end{tabular}

El ancho de las hojas tuvo un promedio general de $8,5 \mathrm{~cm}$, con una desviación estándar de 0,7 cm y un coeficiente de variación de $8,2 \%$. Entre los promedios obtenidos de las poblaciones de plantas tratadas y no tratadas (testigo) no hubo diferencias estadísticas (tabla 1); no obstante, las hojas de las plantas con PBZ fueron ligeramente menos anchas (de 1,6 a 4,4 \%) que las del testigo, lo que indica que el PBZ hizo más eficientes a las plantas por el contenido de clorofila y el proceso fotosintético que por el área foliar ya que, de acuerdo con Sopher et al. (1999), el PBZ ocasiona que en el maíz (en los cultivares 3902 de Pioneer y Orgullo 5) los cloroplastos se hagan más grandes y se aumente el número de lamelas del estroma y el de pilas de grana contenidos, según Salisbury y cada célula de la hoja madura. De tal manera que, en cloroplastos más grandes, con mayor número de lamelas y pilas de grana, se almacena más clorofila en la doble membrana de éstas.

Los incrementos observados en el verdor, la altura, el diámetro de tallos y la longitud de hojas en las plantas tratadas con PBZ también tienen relación con los resultados de Partida et al. (2007) y Velázquez et al. (2008): los primeros obtuvieron mayor verdor, altura y producción de materia seca en las raíces y en la parte aérea de las plantas de pimiento morrón y de berenjena tratadas con PBZ, mientras que los segundos reportaron mayor crecimiento del tallo en plantas de tomate que fueron asperjadas con dosis de 250, 300 o $350 \mathrm{mg}$ de $\mathrm{PBZ} \mathrm{L}^{-1}$ de agua. Por otro 
lado, los resultados en cuanto a las disminuciones de la anchura de hojas también tienen relación con los de Burch et al. (1996), toda vez que ellos observaron que el PBZ reduce la expansión de hojas en muchas especies de árboles.

Además, los incrementos antes referidos son importantes evidencias de que las plantas cultivadas con PBZ fueron más eficaces en la captura de $\mathrm{CO}_{2}$ y así contribuyeron en la mejora del medio ambiente. Sin embargo, cabe anotar que dicha eficacia también fue consecuencia de la mayor actividad genética de las células, ya que, según lo señalado, para metabolizar el nitrógeno y magnesio entre otros nutrimentos, e incrementar la cantidad de moléculas de clorofila, se requirieron más enzimas que solo pudieron sintetizarse, según Strickberger (1978), Conn y Stumpf (1980) y Ferreira et al. (2005), por la transcripción de mensajes del ADN en el ARNm y la traducción de estos en los ribosomas, donde necesariamente también participó mayor cantidad de enzimas en la unión de aminoácidos, como la aminoacil-ARNt sintetasa y la peptidil transferasa, que se constituyeron por la previa síntesis de los aminoácidos necesarios en su composición.

El peso de 1000 granos tuvo un promedio general de 358,4 g, con una desviación estándar de 26,9 g y coeficiente de variación de 7,5 \%. Este carácter se incrementó 1,4, 1,4 y $3,2 \%$ con las respectivas dosis de 150,300 y 450 mg de $\mathrm{PBZ} \mathrm{L}^{-1}$ de agua (tabla 2). El promedio general del volumen de 1000 granos fue de $293 \mathrm{~cm}^{3}$; la desviación estándar, de $27,3 \mathrm{~cm}^{3}$; y el coeficiente de variación, de 9,3\%. Esta característica se incrementó 0,7, 4,9 y 3,5 con las dosis antes mencionadas en relación con el volumen promedio observado en los granos del testigo (tabla 2). Por su parte, el rendimiento de grano nos mostró sin diferencias estadísticas, con un promedio general de 8,8 $\mathrm{t}$ ha ${ }^{-1}$, desviación estándar de 1,9 t ha ${ }^{-1}$ y coeficiente de variación de 19,8\%. En este carácter los incrementos fueron de 12,6, 9,0 y 12,6\% con las respectivas dosis de 150, 300 y $450 \mathrm{mg}$ de PBZ en comparación con el testigo (tabla 2). De tal manera que las diferencias numéricas o en porcentajes indican que las plantas tratadas con PBZ fueron más eficientes para fijar $\mathrm{CO}_{2}$ y acumular materia seca en el órgano de cosecha (grano), por lo que esta tecnología puede ser una alternativa para mejorar el rendimiento de los sistemas de producción agrícola de maíz, a la vez que, por inducir mayor fijación de $\mathrm{CO}_{2}$, también puede ser una tecnología que indirectamente contribuya a que disminuya el deterioro del medio ambiente.

El peso, el volumen y el rendimiento de grano son características que están relacionadas con sustancias como el almidón, los aminoácidos y las proteínas que, según Freifelder (1988) y Lea y Leegood (1993), forman parte de las células vegetales y para cuya síntesis se necesita de mensajes contenidos en el código genético que conforman los codones del ADN. En este orden de ideas, para que los tres caracteres se incrementaran en la forma que se indica en la tabla 2, la demanda de nutrimentos para la síntesis de aminoácidos y proteínas estructurales y enzimas fue mayor y, por tanto, la transcripción de mensajes del ADN en el ARNm y la traducción de estos tuvieron que darse muchas veces más para satisfacer la demanda de las células constituyentes de los granos más pesados, con más volumen y que ocasionaron mayor rendimiento por hectárea.

Tabla 2. Peso, volumen y rendimiento de grano de la variedad Puma Ciclo agrícola 2008-2009. Promedios con letras iguales en la misma columna son iguales.

\begin{tabular}{|c|c|c|c|}
\hline $\begin{array}{r}\text { Dosis de PBZ } \\
\left(\mathrm{mg} \mathrm{L}^{-1}\right)\end{array}$ & $\begin{array}{r}\text { Peso de } 1000 \\
\text { granos }(\mathrm{g})\end{array}$ & $\begin{array}{r}\text { Volumen de } 1000 \\
\text { granos }\left(\mathrm{cm}^{3}\right)\end{array}$ & $\begin{array}{r}\text { Rendimiento } \\
\left(t \text { ha }^{-1}\right)\end{array}$ \\
\hline 0 (testigo) & 350,7 a & $284 \mathrm{a}$ & $8,1 \mathrm{a}$ \\
\hline 150 & 355,5 a & $286 \mathrm{a}$ & $9,1 \mathrm{a}$ \\
\hline 300 & $355,6 \mathrm{a}$ & 298 a & $8,8 \mathrm{a}$ \\
\hline 450 & 361,9 a & $294 \mathrm{a}$ & $9,1 \mathrm{a}$ \\
\hline DMSH & 50,6 & 51,3 & 1,3 \\
\hline
\end{tabular}


Tabla 3. Verdor (unidades SPAD) de tres cultivares tratados con PBZ. Ciclo agrícola 2009-2010. Promedios con letras iguales en la misma columna son iguales.

\begin{tabular}{rrrr}
\hline $\begin{array}{r}\text { Dosis de PBZ } \\
\left(\mathbf{m g ~ L}^{-1}\right)\end{array}$ & Puma & Cultivares \\
\hline 0 (testigo) & $34,8 \mathrm{~b}$ & $34,8 \mathrm{~b}$ & DK2020 \\
150 & $38,1 \mathrm{a}$ & $38,1 \mathrm{a}$ & $34,4 \mathrm{~b}$ \\
300 & $35,9 \mathrm{a}$ & $-\cdots, 7 \mathrm{a}$ \\
450 & $37,8 \mathrm{a}$ & $-\cdots--$ & $-\cdots$ \\
$\mathrm{DMSH}$ & 3,4 & 3,1 & 3,0 \\
\hline
\end{tabular}

Al revisar nuevamente los efectos producidos por el PBZ en el contenido de clorofila de los cultivares Puma, 30P49 y DK2020, en el primero se observó una media general de 38,9 Unidades Spad con una desviación estándar de 3,4 unidades spad y un coeficiente de variación de 8,9 \% (tabla 3), por lo que la clorofila sólo se incrementó 1,8\% con 300 mg de PBZ en relación al testigo. En el cultivar 30P49 la media general fue de 36,3 Unidades Spad, una desviación estándar de 4,1 Unidades Spad y un coeficiente de variación de 11,3\%; de tal manera que en este cultivar el contenido de clorofila no se incrementó en comparación con el testigo. En el cultivar DK2020 la media general fue de 35,6 Unidades Spad con una desviación estándar de 5,7 Unidades Spad y un coeficiente de variación de 16,0 \%, de tal manera que en este cultivar también se incrementó la clorofila en 6,7 \% en las plantas con PBZ en relación al testigo. Los resultados obtenidos en los ciclos 2008-2009 y 2009-2010, permitieron observar que el PBZ indujo incremento del verdor (contenido de clorofila), pero la concentración de esta sustancia no se modificó conforme se incrementó la dosis de PBZ L L de agua.

Tabla 3. Verdor (unidades SPAD) de tres cultivares tratados con PBZ. Ciclo agrícola 2009-2010. Promedios con letras iguales en la misma columna son iguales.

\begin{tabular}{rrrr}
\hline $\begin{array}{r}\text { Dosis de PBZ } \\
\left(\mathrm{mg} \mathrm{L}^{-1}\right)\end{array}$ & Puma & 30P49 & DK2020 \\
\hline 0 (testigo) & $34,8 \mathrm{~b}$ & $34,8 \mathrm{~b}$ & $34,4 \mathrm{~b}$ \\
150 & $38,1 \mathrm{a}$ & $38,1 \mathrm{a}$ & $36,7 \mathrm{a}$ \\
300 & $35,9 \mathrm{a}$ & $-\cdots--$ & $-\cdots--$ \\
450 & $37,8 \mathrm{a}$ & $-\cdots---$ & $-\cdots$ \\
$\mathrm{DMSH}$ & 3,4 & 3,1 & 3,0 \\
\hline
\end{tabular}

La altura del genotipo Puma fue igual entre las plantas con 0 (testigo), 150, 300 o $450 \mathrm{mg}$ de PBZ (tabla 4). En 30P49, la altura también fue similar entre las del testigo y las que solo recibieron $150 \mathrm{mg}$ de PBZ. De igual forma ocurrió entre las plantas del cultivar DK-2020 tratado con la misma dosis 56 de PBZ (150 mg) y las del testigo. Esto permitió confirmar que el PBZ no disminuyó dicho carácter en los tres cultivares utilizados, aplicándolo a partir de la cuarta hoja verdadera, quizás porque las giberelinas existen en mayor concentración en plantas con las etapas fenológicas consideradas en esta investigación, aunque este regulador sea conocido como inhibidor de las giberelinas en los puntos de crecimiento. 
La longitud de hojas en el cultivar Puma tuvo un promedio general de 94,8 cm con desviación estándar de 5,2 cm y coeficiente de variación de $5,5 \%$. No obstante solo ocurrieron diferencias numéricas, la longitud se incrementó de $3,1-3,2 \%$ con 150 o 450 mg de PBZ en comparación con la longitud de hojas del testigo (tabla 5). El cultivar DK2020 presentó un promedio general de $94,4 \mathrm{~cm}$ con una desviación estándar de 4,1 cm y un coeficiente de variación de $4,4 \%$; sin embargo, esta variable disminuyó $1,6 \%$ en las plantas tratadas con $150 \mathrm{mg}$ de PBZ comparadas con el testigo. No obstante, 30P49 mostró un promedio de 84,3 $\mathrm{cm}$, la desviación estándar fue de $4,2 \mathrm{~cm}$, y el coeficiente de variación fue de 5,0 \%, pero en las plantas tratadas con PBZ disminuyó 1,2 \% con respecto a las del testigo.

La anchura de las hojas de Puma tuvo un promedio de 9,6 cm con desviación estándar de 1,3 cm y coeficiente de variación de $13,5 \%$, mientras que en 30P49 el promedio fue de 10,2 cm con desviación estándar de 0,6 cm y coeficiente de variación de $6,3 \%$, en tanto que en DK2020 los valores fueron de $9,8,0,8 \mathrm{~cm}$ y $8,4 \%$, respectivamente. Sin embargo, esta variable fue ligeramente menor en Puma y 30P49; en cambio, en DK2020 fue a la inversa.

Cuando se aplicaron diferentes dosis de PBZ (tabla 6), el contenido de proteína se observó sin diferencias significativas en el cultivar Puma, y el incremento máximo que se obtuvo fue de 6,1\% en el grano de las plantas en que se aplicaron $300 \mathrm{mg}$ de PBZ, en comparación con el contenido proteico del testigo. Sin embargo, la correlación del contenido de proteína con el rendimiento de grano fue negativa $(\mathrm{r}=-0,67)$, lo cual coincidió con lo reportado por Loffler et al. (1985) en cuanto a la correlación negativa del contenido de proteína y el rendimiento de granoen trigo.

Tabla 4. Altura (m) de planta de tres cultivares de maíz tratado con PBZ en etapas de cuatro, seis y ocho hojas verdaderas en el cultivar Puma, y en la de cuatro para 30P49 y DK2020. Ciclo agrícola 2009-2010. Promedios con letras iguales en la misma columna son iguales.

\begin{tabular}{rrrr}
\hline $\begin{array}{r}\text { Dosis de PBZ } \\
\left(\mathbf{m g ~ L}^{-1}\right)\end{array}$ & Puma & $\begin{array}{r}\text { Cultivares } \\
\mathbf{3 0 P 4 9}\end{array}$ & DK2020 \\
\hline 0 (testigo) & $1,9 \mathrm{a}$ & $2,0 \mathrm{a}$ & $2,0 \mathrm{a}$ \\
150 & $1,9 \mathrm{a}$ & $2,0 \mathrm{a}$ & $2,0 \mathrm{a}$ \\
300 & $1,9 \mathrm{a}$ & $-\cdots---$ & $-\cdots---$ \\
450 & $1,8 \mathrm{a}$ & $-\cdots---$ & ---- \\
\hline
\end{tabular}

Tabla 5. Longitud (L) y ancho (A) (cm) de hojas en tres cultivares de maíz. Ciclo agrícola 2009-2010. Promedios con letras iguales en la misma columna son iguales (Tukey $\leq 0,05$ ).

\begin{tabular}{|c|c|c|c|c|c|c|}
\hline \multirow{3}{*}{$\begin{array}{r}\text { Dosis de PBZ } \\
\left(\mathrm{mg} \mathrm{L}^{-1}\right)\end{array}$} & \multicolumn{6}{|c|}{ Cultivares } \\
\hline & \multicolumn{2}{|r|}{ Puma } & \multicolumn{2}{|r|}{$30 P 49$} & \multicolumn{2}{|c|}{ DK2020 } \\
\hline & L & A & $\mathrm{L}$ & A & $\mathrm{L}$ & A \\
\hline 0 (testigo) & $92,6 \mathrm{a}$ & $9,5 \mathrm{a}$ & $84,8 \mathrm{a}$ & 10,4 a & $95,2 \mathrm{a}$ & $9,8 \mathrm{a}$ \\
\hline 150 & $95,5 \mathrm{a}$ & $10,2 \mathrm{a}$ & $83,8 \mathrm{a}$ & $10,1 \mathrm{a}$ & $93,7 \mathrm{a}$ & $9,7 \mathrm{a}$ \\
\hline 300 & $95,5 \mathrm{a}$ & $9,3 \mathrm{a}$ & -------- & ------- & ------- & ------- \\
\hline 450 & $95,6 \mathrm{a}$ & $9,5 \mathrm{a}$ & -------- & ------- & -------- & ------- \\
\hline DMSH & 3,8 & 1,0 & 2,7 & 0,4 & 2,7 & 0,5 \\
\hline
\end{tabular}


Tabla 6. Contenido de proteína (\%) del grano del cultivar Puma y rendimiento ( $\left.\mathrm{t} \mathrm{ha}^{-1}\right)$ de grano de tres cultivares de maíz. Ciclo agrícola 2009-2010. Promedios con letras iguales en la misma columna son iguales (Tukey $\leq 0,05$ ).

\begin{tabular}{rrrrr}
\hline $\begin{array}{r}\text { Dosis de PBZ } \\
\left(\mathbf{m g ~ L}^{-1}\right)\end{array}$ & Proteína & $\begin{array}{r}\text { Cultivares } \\
\text { Puma }\end{array}$ & $\begin{array}{r}\mathbf{3 0 P 4 9} \\
\text { Rendimiento }\end{array}$ & $\begin{array}{r}\text { Rendimiento } \\
\text { DK2020 } \\
\text { Rendimiento }\end{array}$ \\
\hline 0(testigo) & $11,4 \mathrm{a}$ & $10,8 \mathrm{ab}$ & $9,7 \mathrm{a}$ & $11,0 \mathrm{a}$ \\
150 & $11,7 \mathrm{a}$ & $8,2 \mathrm{~b}$ & $9,9 \mathrm{a}$ & $11,1 \mathrm{a}$ \\
300 & $12,1 \mathrm{a}$ & $9,6 \mathrm{ab}$ & $-\cdots---$ & $-\cdots$ \\
450 & $11,3 \mathrm{a}$ & $12,5 \mathrm{a}$ & $-\cdots----$ & $-\cdots$ \\
DMSH & 4,3 & 3,4 & 3,4 & 4,8 \\
\hline
\end{tabular}

El rendimiento del cultivar Puma tuvo un promedio general de 10,3 t, con desviación estándar de 1,8 t y un coeficiente de variación de $17,4 \%$, pero el mayor rendimiento se obtuvo con la dosis de $450 \mathrm{mg}$ de PBZ, cuyo incremento fue 15,7 \% más con relación al testigo. No obstante, con 150 y 300 mg de PBZ el rendimiento disminuyó 24,1 \% y 11,1 \%, respectivamente, lo que a su vez confirmó la correlación negativa entre el contenido de proteína y el rendimiento de grano mencionada por Loffler et al. (1985). Con el cultivar 30P49, el promedio general de rendimiento fue de 9,8 t, con una desviación estándar de 1,5 y coeficiente de variación 15,5 \%; sin embargo, con los 150 mg de PBZ que se aplicaron solo se logró un incremento de 2,1\% con respecto al testigo. Finalmente, el cultivar DK2020 expresó un rendimiento promedio general de $11,1 \mathrm{t}$, con desviación estándar de 2,7 t y un coeficiente de variación de $24,8 \%$, pero con $150 \mathrm{mg}$ de PBZ, única dosis aplicada, el incremento fue de apenas $0,9 \%$ comparado con el testigo.

Lo anterior permitió deducir que la respuesta de los cultivares de maíz varió según la dosis de PBZ y el manejo que se les dió, como en el caso del cultivar Puma, pero también dicha respuesta fue diferente entre cultivares, lo cual es de comprenderse si se toma en cuenta que son genotipos diferentes, ya que los progenitores son distintos. Esto también conllevó a la deducción de que para que se incrementara el contenido de proteína y el rendimiento de grano, aún en las cantidades que se indican en la tabla 6 , debió incrementarse la actividad genética para que la síntesis de proteínas se diera con mayor frecuencia al transcribirse mayor cantidad de mensajes del ADN en el ARNm y traducirlos en los ribosomas con la acción de los ARNt y ARNr, así como 58 de todas las enzimas necesarias para la síntesis de proteínas, como lo explica Strickberger (1978). Esto es, el PBZ activa al material genético no solo para la síntesis de proteínas estructurales, sino también para la síntesis de proteínas activas (enzimas), ya que estas últimas se requieren para la síntesis de las primeras y de los respectivos aminoácidos. Además, el incremento del rendimiento de grano dejó en evidencia que, para formar más granos y producir más kilogramos de grano por hectárea, fueron necesarias más moléculas proteicas, que luego formaron parte de las membranas y paredes, entre muchas otras partes celulares más.

Al considerar las toneladas de grano que produjo el cultivar de maíz Puma (tabla 6), se estimó que el 11,4% de proteína en el grano del testigo fue equivalente a 1231,4 kg de grano, en tanto que el $11,3 \%$ de proteína en el grano del mismo cultivar manejado con PBZ equivalió a 1412,5 kg de grano. Esto último correspondió a un incremento de 14,7 \% con respecto al testigo, lo cual también es evidencia de que en el cultivar Puma se produjeron más proteínas como consecuencia de la mayor actividad genética que promovió el PBZ. Algo similar ocurrió en los cultivares 30P49 y DK2020, aunque en porcentajes de 2,1 y 0,9 , respectivamente.

El PBZ ocasionó incremento en la mayoría de las variables evaluadas en los cultivares de maíz. Esto indicó que para que eso sucediera fue necesario un aumento de la actividad genética de las células de los cultivares y, por tanto, más transcripción de mensajes en el ARNm, síntesis de aminoácidos, transportación de estos por el ARNt, unión de aminoácidos por la enzima peptidil transferasa y traducción de mensajes en proteínas estructurales y activas (enzimas), para formar más células y sustancias que constituyen a estas, lo que genera más rendimiento de grano por hectárea. 


\section{Referencias}

Burch, P.L., Wells, R.H. y Kline W.N. 1996. Red maple and silver maple growth evaluated 10 years after application of paclobutrazoltree growth regulator. Journal Arboriculture 22: 61-66.

Conn, E.E. y Stumpf, P.K. 1980. Bioquímica Fundamental. Editorial Limusa, S. A. México, D. F.

Ferreira, V., Szpiniak, B. y Grassi, E. 2005. Manual de Genética, Tomo I. Universidad Nacional de Río Cuarto, Córdoba.

Freifelder, D. 1988. Fundamentos de Biología Molecular. Editorial Acribia S. A., Zaragoza.

Gopi, R., Abdul, J.Ch., Divyanair, V., Azooz, M.M. y Panneerselvam, R. 2009. Effect of paclobutrazol and ABA on total phenol contents in different parts of Holy Basil (Ocimum sanctum). Academic. Journal of Plant Sciences 2(2): 97-101.

Goulston, G.H. y Shearing, S.J. 1985. Review of the effects of Paclobutrazol on ornamental pot plants. Acta Horticulturae 167: 339-348.

Iremiren, G.O., Adewumi, P.O., Aduloju, S.O. y Ibitoye, A.A. 2002. Effects of Paclobutrazol and nitrogen fertilizer on the growth and yield of maize. Journal of Agricultural Science 128: 425-430.

Lea, P.J. y Leegood, R.C. 1993. Plant Biochemistry and Molecular Biology. Editorial John Wiley \& Sons, Nueva York.

LeCain, D.R., Schekel, K.A. y Walple, R.L. 1986. Growth retarding effects of paclobutrazol on weeping fig. HortScience 21: $1150-1152$.

Loffler, C.M., Rauch, T.L. y Busch, R.H. 1985. Grain and plant protein relationships in hard red spring wheat. Crop Science 25: 521-524.

Nizam, K. y Te-chato, S. 2009. Optimizing of root induction in oil palm plantlets for acclimatization by some potent plant growth regulators (PGRs). Journal of Agricultural Technology 5(2): 371-383.
Ochoa, J., Franco, J.A., Bañón, S. y Fernández, J.A. 2009. Distribution in plant, substrate and leachate of Paclobutrazol following application to containerized Nerium oleander L. seedlings. Spanish Journal of Agricultural Research 7(3): 621-628.

Partida, R.L., Velázquez, A.T. de J., Acosta, V.B., Ayala, T.F., Díaz, V.T., Inzunza, C.J.F. y Cruz, O.J.E. 2007. Paclobutrazol y crecimiento de raíz y parte aérea de plántulas de pimiento morrón y berenjena. Revista Fitotecnia Mexicana 30(2): 145-149.

Possingham, J.V. 1980. Plastid replication and development in the life cycle of higher plants. Annual Review of Plant Physiology 31: 113-129.

Salisbury, F.B. y Ross, C.W. 2000. Fisiología de las Plantas. Paraninfo Thomson Learning, Madrid, España. SAS Institute. 1996. SAS User's Guide: Basics, 5th Edition. SAS Institute Inc., Cary, N. C.

Sopher, C.R., Król, M., Huner, N.P.A., Moore, A.E. y Fletcher R.A. 1999. Chloroplastic changes associated with Paclobutrazol-induced stress protection in maize seedlings. Canadian Journal Botany 77(2): 279-290.

Strickberger, M.W. 1978. Genética. Ediciones Omega, S. A. Imprenta Juvenil S. A. Barcelona.

Tadao, A., Kin, M.Y., Nagata, N., Yamagishi, K., Takatsuto, S., Fujioka, S., Murofushi, N., Yamaguchi, I. y Yoshida S. 2000. Characterization of brassinazole, a triazole-type brassinosteroid biosynthesis inhibitor. Plant Physiology 123(1): 93-99.

Velázquez, A.T. de J., Partida, R.L., Acosta, V.B. y Ayala, T.F. 2008. Producción de plantas de tomate y Chile aplicando Paclobutrazol al follaje. Universidad y Ciencia 24(1): 21-28.

Wilkinson, R.I. y Richards, D. 1988. Influence of Paclobutrazol on growth and flowering of Camellia $\mathrm{x}$ williamsii. HortScience 23(2): 359-360.

Wood, B.W. 1988. Paclobutrazol suppresses vegetative growth of large pecan trees. HortScience 23(2): 341-343.

Citar como: Velázquez-Alcaraz, T., Díaz-Valdés, T., Ayala-Tafoya, F., Yáñez-Juárez M.G., Partida-Ruvalcaba L., Medina-López, R. y López-Orona, C.A. Respuestas del maíz que indican que el paclobutrazol induce mayor actividad genética Intropica 14(1): 51-59. DOI: http://dx.doi.org/10.21676/23897864.2765. 